\title{
Company Profile Pada Kantor Desa Lumpatan 1 Berbasis Web
}

\author{
Nopita Lestari, Zaid Romegar Mair \& Ali Subhan Afrizal \\ Teknik Informatika Politeknik Sekayu \\ Email : nopitalestari0608@gmail.com
}

\begin{abstract}
The Lumpatan 1 Village Office which is located on Jl.Betung-Sekayu, Lumpatan, Sekayu, Musi Banyuasin Regency is the Lumpatan I Village Office for the Musi Banyuasin Regency, South Sumatra Province. This office has a duty as community service for the Musi Banyuasin area. However, this office does not yet have electronic media to convey information to the public, so it is difficult for people to find information about the office. So far, to find information about this office, people still come to the office directly without any media connecting the community with this office. In this study the method used is the Waterfall method which consists of five stages, namely: Needs Analysis, System Design, Coding, Testing or Implementation, and Maintenance. With this Company Profile, it will be useful for the Lumpatan 1 Village Office and users (Community) because it is a medium of information or a liaison between the office and the community. This Company Profile was built using the PHP and MySQL programming languages as a medium for delivering data and the web server is localhost PHP Myadmin
\end{abstract}

Keywords: Waterfall, Company Profile, PHP, MySQL

\section{Pendahuluan}

Internet merupakan salah satu fenomena paling berpengaruh dalam beberapa dekade terakhir ini, baik bagi perkembangan teknologi itu sendiri maupun bagi perkembangan disiplin ilmu lain, seperti ekonomi, politik, sosial dan budaya. Perkembangan internet juga berpengaruh langsung terhadap perkembangan situs web. Informasi disampaikan melalui sebuah portal yang disebut dengan website. Website adalah sebuah portal yang bisa diakses melalui internet dari mana saja dan kapan saja. Salah satu media penyampaian informasi suatu perusahaan atau instansi pemerintah adalah website company profile. Website company profile adalah sebuah website yang menampilkan informasi tentang latar belakang sebuah perusahaan, produk atau layanan, informasi kontak dan berita singkat seputar perusahaan

Kantor Kepala Desa Lumpatan 1 yang berada dikecamatan Sekayu merupakan salah satu instansi pemerintah yang bergerak dibidang pelayanan masyarakat, namun dalam kinerja pelayanan masyarakat kantor desa ini memiliki kendala dan permasalahan yaitu belum adanya ketersedian informasi yang dapat diakses secara mudah oleh masyarakat. Penyampaian informasi yang selama ini digunakan kebanyakan menggunakan cara konvensional. Cara konvensional tersebut antara lain penyampaian informasi dengan pemasangan spanduk dan melalui papan pengumuman.

Dari identifikasi perumusan yang muncul dikantor Desa Lumpatan 1. Maka, penulis menyarankan agar dapat meningkatkan kualitas informasi juga memberikan informasi kepada masyarakat yang terpercaya dan akurat melalui media website secara online. sehingga masyarakat dapat mengetahui perkembangan pembangunan dan infrastruktur serta informasi penting seputar Desa Lumpatan 1 yang dapat diakses dengan cepat dan mudah di laman website. Sehingga masyarakat pun akan merasa terbantu dan diberikan pelayanan secara maksimal dengan adanya website Profil Desa Lumpatan 1. 
Berdasarkan latar belakang yang telah diuraikan, maka penulis mengidentifikasi masalah yang dihadapi oleh Kantor Desa Lumpatan 1 sehingga perumusan masalah yang didapat yaitu Bagaimana membuat sebuah company profile sebagai media informasi Kantor Desa Lumpatan 1 agar dapat mudah digunakan dan dipahami oleh masyarakat luas.

\section{Tinjauan Literatur}

\subsection{Aplikasi}

Menurut Mainunah dkk. Dalam jurnal CCIT Vol.5 No.3 (2012 : 284) Company Profile adalah sebuah aset suatu lembaga atau perusahaan yang dapat digunakan untuk meningkatkan suatu image atau citra dari perusahaan untuk menjalin kerja sama dengan relasi perusahaan, lembaga dan instansi yang terkait lainnya.

Menurut Binanto dalam (Dewo dan Dewi, 2019) Company Profile adalah identitas suatu perusahaan, baik dalam bidang jasa maupun produk yang bertujuan untuk mengimpirmasikan, mempengaruhi dan membujuk, serta mengingatkan kepada pelanggan tentang perusahaan.

Berdasarkan pendapat para ahli tersebut penulis dapat menyimpulkan bahwa company profile adalah sebuah aset perusahaan untuk memperkenalkan latar belakang perusahaan dan hal yang terkait dengan perusahaan yang dimuat dalam sebuah website.

\subsection{Internet}

Menurut Dimuksa, dkk (2013:08) internet dapat diterjemahkan Interconnection Networking yang berarti hubungan komputer dengan berbagai tipe yang membentuk sistem jaringan yang mencakup seluruh dunia dengan melalui jalur telekomunikasi seperti telepon, radio, link, dan lain-lain..

Menurut Sibero (2013:10) Internet yaitu kepanjangan dari Interconnection Networking adalah jaringan computer yang menghubungkan antar jaringan secara global internet dapat juga disebut jaringan dalam satu jaringan yang luas.

Berdasarkan pendapat para ahli maka kesimpulan yang dapat diambil dari pengertian Internet adalah Interconnection Networking yang berarti hubungan komputer dengan berbagai tipe yang membentuk sistem jaringan yang mencakup seluruh dunia

\subsection{Website}

Menurut Yuhefizar, (2013:2) Website adalah keseluruhan halaman-halaman web yang terdapat dalam domain yang mengandung informasi. Sebuah website biasanya dibangun atas abnyak halaman web yang saling berhubungan.

M. Rudyanto Arief, (2011:7) Website adalah salah satu aplikasi yang berisikan dokumendokumen multimedia (teks, gambar, suara, animasi, video) didalamnya yang menggunakan protokol HTTP (hyper text transfer protocol ) dan untuk mengaksesnya mengunakan perangkat lunak yang disebut browser.

Kesimpulannya website adalah sebuah informasi yang ditampilkan melalui internet yang biasanya menggunakan web browser untuk mengaksesnya dan kumpulan halaman web yang berisikan informasi dan berada di sebuah domain.

\subsection{HRML (Hypertext Markup Language)}

Menurut Djaelangkara, dkk (2015:87) HTML (Hypertext Markup Language) adalah sebuah bahasa markah yang digunakan untuk membuat sebuah halaman web, 
menampilkan berbagai informasi di dalam sebuah penjelajah web dan pemformatan hiperteks yang sederhana yang ditulis dalam berkas format ASCII agar dapat menampilkan wujud yang terintegrasi.

Menurut Sibero (2013:19) mengatakan bahwa Hypertext Markup Language atau HTML adalah bahasa yang digunakan pada dokumen web sebagai bahasa untuk pertukaran dokumen web

Jadi berdasarkan pengertian tersebut dapat disimpulkan $H T M L$ adalah bahwa sebuah bahasa markah yang digunakan untuk membuat sebuah halaman web, menampilkan berbagai informasi di dalam sebuah penjelajah web dan pemformatan

\section{2,5 PHP (Hypertext Preprocessor)}

Menurut Supono dan Putratama (2016:3) mengemukakan bahwa PHP (Hypertext Preprocessor) adalah suatu bahasa pemrograman yang digunakan untuk menerjemahkan baris kode program menjadi kode mesin yang dapat dimengerti oleh komputer yang berbasis server-side yang dapat ditambahkan ke dalam HTML.

Menurut Sibero (2013:49) mengatakan bahwa $P H P$ adalah pemrograman interpreter yaitu proses penerjemahan baris kode sumber menjadi kode mesin yang dimengerti komputer secara langsung pada saat baris kode dijalankan.

Berdasarkan definisi diatas dapat ditarik kesimpulan bahwa MySQL merupakan perangkat lunak yang mempermudah dalam pengolahan database. Dan untuk menjalankan fungsi pengolahan data dan merupakan Oracle, $M S S Q L$, Postagre $S Q L$ yang terdapat dalam Database Management System (DBMS).

\subsection{Sublime Text 3}

Menurut Hadiningrum dan Ema (2015:2) Sublime adalah text editor terbaru yang memiliki fitur pendukung untuk beberapa bahasa pemprograman seperti PHP, Python, Java, HTML, Ruby, Perl, SQL. Dan C++

Menurut Prasetyo (2016:6:23) Sublime Text 3 adalah sebuah text/source editor yang memudahkan kita saat melakukan coding dan support terhadap banyak bahasa pemprograman mulai dari ASP, C++, C\#, PHP, HTML dan masih banyak lagi.

Dari penjelasan tersebut dapat disimpulkan bahwa Sublime Text adalah text/source editor yang memiliki fitur pendukung untuk beberapa bahasa pemprograman kita saat melakukan coding.

\subsection{Basis Data}

Menurut Djaelangkara, dkk (2015:87) basis data merupakan komponen terpenting dalam pembangunan sistem informasi, karena menjadi tempat untuk menampung dan mengorganisasikan seluruh data yang ada di dalam sistem.

Menurut Rossa dan Shalahudin (2015:43) basis data adalah sistem terkomputerisasi yang tujuan utamanya adalah memelihara data yang sudah diolah atau informasi dan membuat informasi tersedia saat dibutuhkan.

Berdasarkan teori diatas basis data adalah merupakan komponen terpenting dalam pembangunan sistem informasi, karena menjadi tempat untuk menampung dan mengorganisasikan seluruh data sistem terkomputerisasi yang tujuan utamanya adalah memelihara data yang sudah diolah atau informasi dan membuat informasi yang saling 
berhubungan dan disimpan dalam media penyimpanan secara digital (Antoni, Fikari \& Akbar, 2018; Antoni \& Akbar, 2019; Antoni, Jie \& Abareshi, 2020; Antoni, Herdiansyah, Akbar \& Sumitro, 2021).

\subsection{MySQL (My Structure Query Language)}

Menurut Djae(2010:97) MySQL adalah sebuah implementasi dari manajemen basis data relasional RDBMS yang didistribusikan secara gratis dibawah lisensi GPL (General Public License).

Menurut Raharjo, dkk (2012, p.216), MySQL merupakan sistem database yang banyaj digunakan untuk pengembangan aplikasi web. Alasanya mungkin karena grafis, pengolaan datanya sedehana, memiliki tingkat keamanan yang bagus, mudah diperoleh dan laini-lain.

Berdasarkan definisi diatas dapat ditarik kesimpulan bahwa $M y S Q L$ merupakan perangkat lunak yang mempermudah dalam pengolahan database.

\subsection{CSS (Cascading Style Sheet)}

Menurut Djaelangkara, dkk (2015:87) Cascading Style Sheets (CSS) merupakan aturan untuk mengendalikan beberapa komponen dalam sebuah web sehingga akan lebih terstruktur dan seragam.

Menurut Sibero (2013:112) mengatakan bahwa Cascading Style Sheets memiliki arti gaya menata halaman bertingkat, yang berarti setiap satu elemen yang telah di format, dan memiliki anak dan telah di format, maka anak dari elemen tersebut secara otomatis mengikuti format elemen induknya.

Berdasarkan pendapat para ahli maka penulis menyimpulkan CSS (Cascading Style Sheets) merupakan aturan untuk mengendalikan beberapa komponen dalam sebuah web sehingga akan lebih terstruktur skrip yang berisi rangkaian intruksi ya2.ng menentukan suatu teks.

\subsection{XAMPP (X Apache Mysql Php Perl)}

Menurut Purbadian (2016:1), XAMPP merupakan suatu software yang bersifat open source yang merupakan pengembangan dari LAMP (Linux, Apache, MySQL, PHP dan Perl).

Menurut Kartini (2013:27-26) XAMPP merupakan tool yang menyediakan paket perangkat lunak ke dalam satu buah paket.

Kesimpulan yang dapat diambil $X A M P P$ adalah tool pembantu pengembangan paket perangkat lunak berbasis open source yang menggabungkan Apache web server, MySQL, PHP dan beberapa modul lainnya di dalam satu paket aplikasi.

\section{2. $11 U M L$}

Menurut Rosa dan Shalahuddin (2014:133), berpendapat bahwa UML (Unified Modeling Language) adalah Salah standar bahasa yang banyak digunakan di dunia industri untuk mendefinisikan requerement, membuat analisa \& desain, serta menggambarkan arsitektur dalam pemrograman berorintasi objek.

Menurut Mulyani (2016:48) mengatakan UML (Unified Modeling Language) adalah Sebuah teknik pengembangan sistem yang menggunakan bahasa grafis sebagai alat untuk pendokumentasian dan melakukan spesifikasi pada sistem.

Jadi dapat disimpulkan bahwa UML (Unified Modeling Language) adalah bahasa yang 
sering digunakan untuk membangun sebuah sistem perangkat lunak dengan melakukan penganalisaan desain dan spesifikasi dalam pemrograman berorintasi objek.

\subsection{Teori Pengujian Perangkat Lunak}

Proses tahapan Proses tahapan pengujian adalah sebuah proses terhadap aplikasi/program untuk menemukan segala kesalahan dan segala kemungkinan yang akan menimbulkan kesalahan sesuai dengan spesifikasi perangkat lunak yang telah ditentukan sebelum aplikasi tersebut diserahkan kepada pengguna.Ada beberapa jenis metode untuk melakukan pengujian perangkat lunak, yaitu:

\subsubsection{Black Box Testing}

Black box testing adalah pengujian yang dilakukan untuk mengetahui kesalahan fungsionalitas fitur pasa sebuah aplikasi. Black box testing terfokus pada apakah unit program memenuhi kebutuhan (requirement) yang disebutkan dalam spesifikasi. Pada black box testing, cara pengujian hanya dilakukan dengan menjalankan atau mengeksekusi unit atau modul, kemudian diamati apakah hasil dari unit itu sesuai dengan proses yang diinginkan.

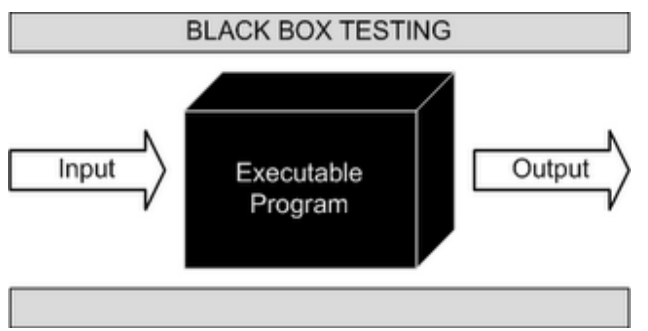

Gambar 2.1 Pengujian Metode Black Box Testing

\section{Metode Penelitian}

\subsection{Spesifikasi Kebutuhan Perangkat}

Spesifikasi yang digunakan untuk merancang dan membangun Company Profile Kantor Desa Lumpatan 1 ini meliputi dua hal yaitu Perangkat Keras (Hardware) dan Perangkat Lunak (Software)

\subsubsection{Spesifikasi Kebutuhan Perangkat Keras (Hardware)}

Perangkat keras yang digunakan dalam pembangunan Company Profile ini adalah laptop dengan spesifikasi sebagai berikut :
1) Processor
:Intel ${ }^{\circledR}$ Celeron ${ }^{\circledR N} 3350$
2) Memory :2,00GB RAM
3) Harddisk : $500 \mathrm{~GB}$
4) Monitor : 14.00"

@ $2.16 \mathrm{GHz}$

\subsubsection{Kebutuhan Perangkat Lunak (Software)}

Perangkat lunak yang digunakan untuk membuat Company Profile Pada Kantor Desa Lumpatan 1 adalah sebagai berikut

1) Sistem Operasi : Windows 10

2) Xampp 
3) Web server: Apache

4) Web editor: Sublime text 3

5) Web browser : Google Chrome

6) Database Server : Mysql

7) Remote Database : PhpMyAdmin

8) File Server : Filezilla

9) PHP : v3.2.1

\section{2 Perancangan Struktur Menu}

Pembuatan bagian ini bertujuan untuk mempermudah membaca menu dari Company Profile Kantor Desa Lumpatan 1. Adapun struktur menu dapat dilihat dari gambar berikut :

1) Menu Masyarakat

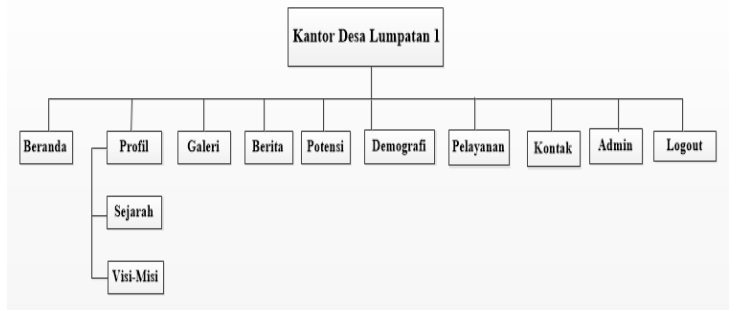

Gambar 3.1 Menu Masyarakat

Pada gambar 3.1 menjelaskan struktur menu dibagi menjadi beberapa fungsi yang dirancang dalam beberapa menu yang bertujuan untuk memudahkan penggguna dalam melihat isi dari sistem ini.

2) Menu Admin

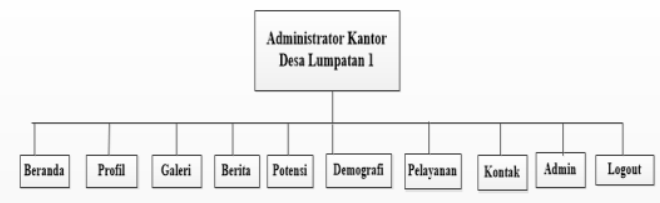

Gambar 3.2 Menu Admin

Pada gambar 3.2 menjelaskan halaman untuk admin yang dirancang untuk memudahkan admin dalam mengisi berita atau informasi terbaru dan juga dalam mengelolah data user.

\subsection{Perancangan Sistem}

Perancangan Sistemyaitu menggambarkan mengenai sistem yang akan dibuat maka alat bantu yang digunakan dalam perancangan sistem berupa Unifed Modelling Language (Use Case Diagram, Activity Diagram, Class Diagram).

\section{1) Use Case Diagram}




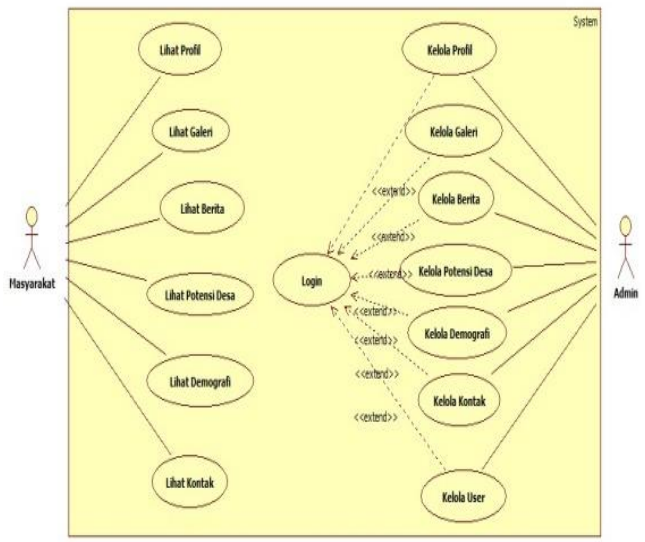

Gambar 3.3 Use Case Diagram

Pada Gambar 3.3 Pada use case diagram terdapat beberapa aktifitas yang dapat dilakukan oleh admin maupun masyarakat (pengguna). Khusus untuk admin untuk masuk ke sistem ini, admin harus melakukan login terlebih dahulu sebelum melakukan proses atau aktifitas.

2) Activity Diagram

a) Activity Diagram Login

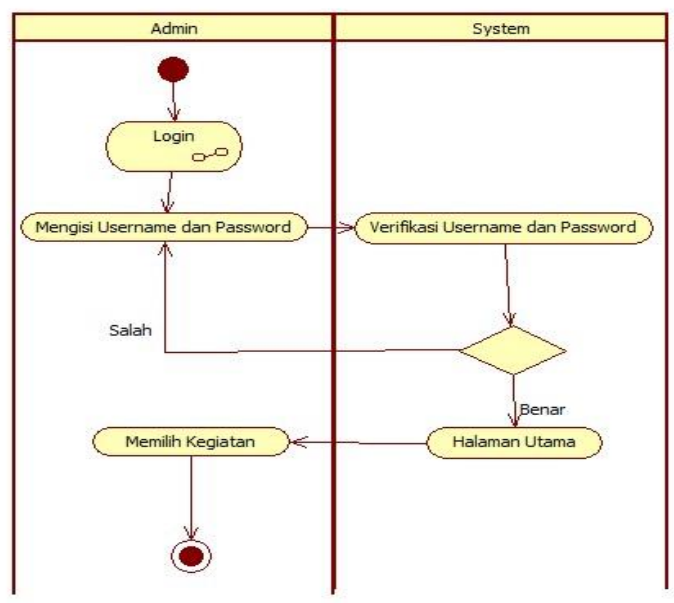

Gambar 3.4 Activity Diagram Login

Pada gambar 3.4 Pada gambar diatas menjelaskan alur Login Admin dari input form username dan password lalu system akan memverifikasi login, jika username dan password benar maka system akan menuju ke halaman utama admin dan jika salah maka admin mengulangi mengisi username dan password. 
b) Activity Diagram Kelola Profil

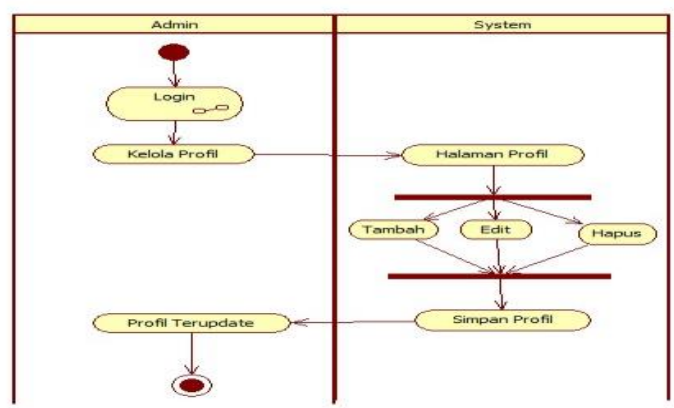

Gambar 3.5 Activity Diagram Kelola Profil

Pada gambar 3.5 menjelaskan alur proses Admin mengelolah profil, admin akan memilih menu profil dan system akan menuju kehalaman kelola profil, admin biasa menambah, mengedit dan menghapus profil selanjutnya setelah data berhasil disimpan, maka akan diperoleh profil terbaru (terupdate).

3) ERD

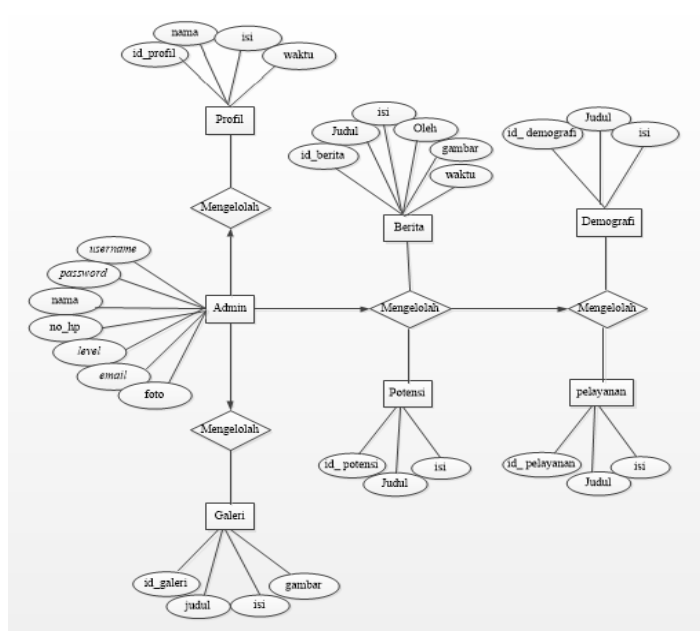

Gambar 3.6 ERD

Pada Gambar 3.6 Gambar diatas merupakan gambar perancangan database (ERD) dari sistem yang akan dibangun. Pada gambar diatas terdapat 7 entitas, yaitu admin, profil, galeri, berita, potensi desa,demografi desa,pelayanan surat dan kontak. Selain itu, terdapat 4 buah relasi yang menghubungkan satu entitas dan entitas lainnya.

\section{Hasil dan Pembahasan}

\subsection{Hasil}

Hasil dari penulisan dan pengerjaan laporan tugas akhir ini adalah sebuah company profile berbasis web pada Kantor Kepala Desa. Web ini diharapkan dapat membantu staff kantor Desa dalam menyampaikan informasi mengenai Kantor Desa itu sendiri.

Company Profile yang dibangun memiliki dua halaman utama yaitu halaman masyarakat dan halaman Admin terdapat beberapa menu yang bias di akses yaitu Beranda, Profil, Galeri, Berita, Potensi Desa, Demografi Desa, Pelayanan Surat dan Kontak. Dan sebelum masuk ke halaman admin akan tampil form login untuk administrator. Kemudian 
administrator dapat melakukan aksesnya yaitu input, edit, dan hapus data pada menu admin.

\subsection{Pengujian Aplikasi}

\subsubsection{Halaman Administrator}

1) Tampilan Login

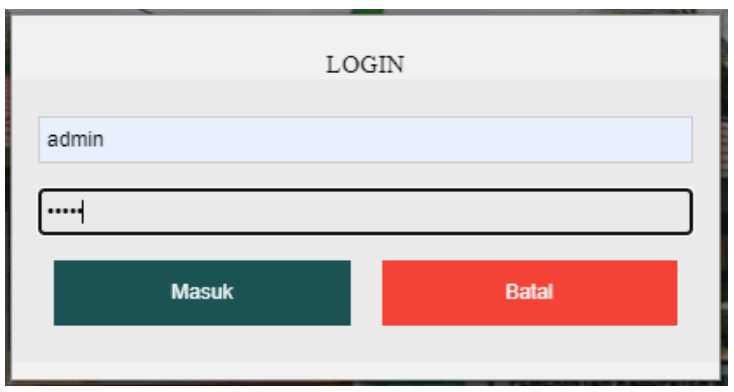

Gambar 4.1 Tampilan login

2) Halaman Beranda

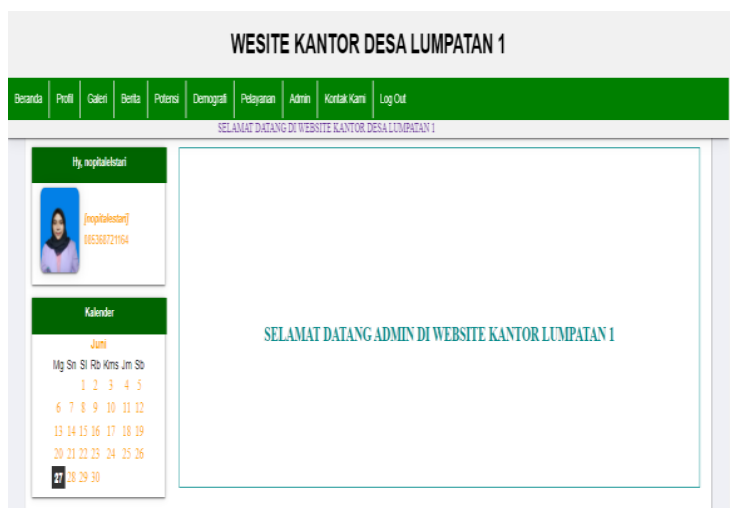

Gambar 4.2 Halaman Beranda

3) Halaman Menu Profil Sejarah

a) Tampilan Lihat Data Sejarah

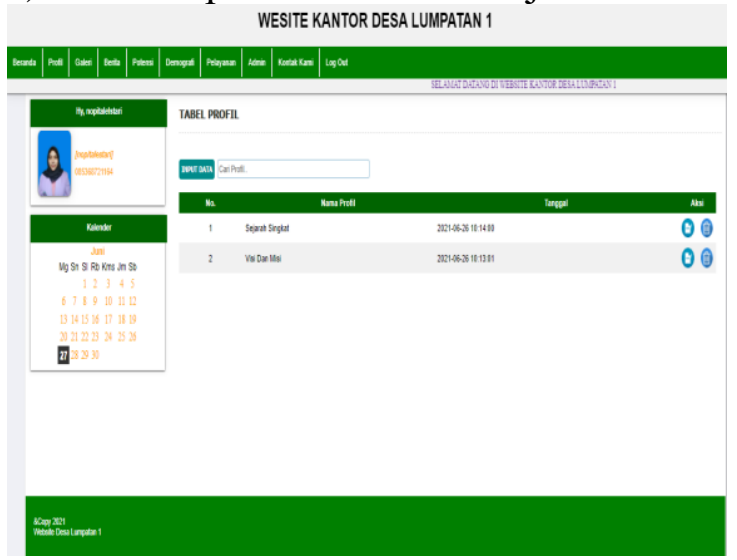

Gambar 4.3 Tampilan Lihat Data Sejarah

Published by: 
b) Tampilan Input Data Sejarah

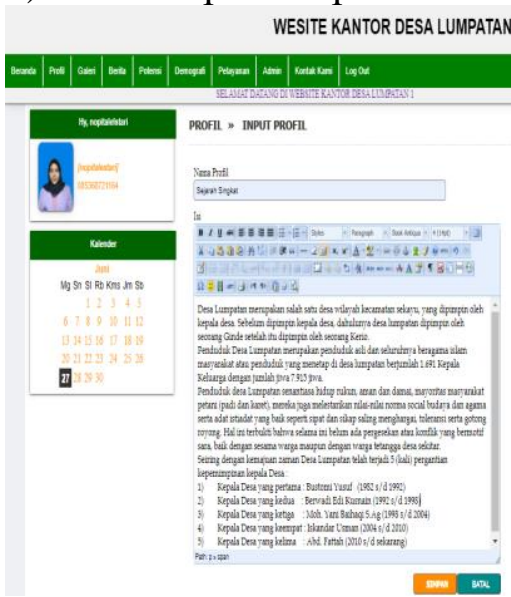

Gambar 4.4 Tampilan Input Data Sejarah

c) Tampilan Edit Data Sejarah

WESITE KANTOR DESA LUMPATAN 1

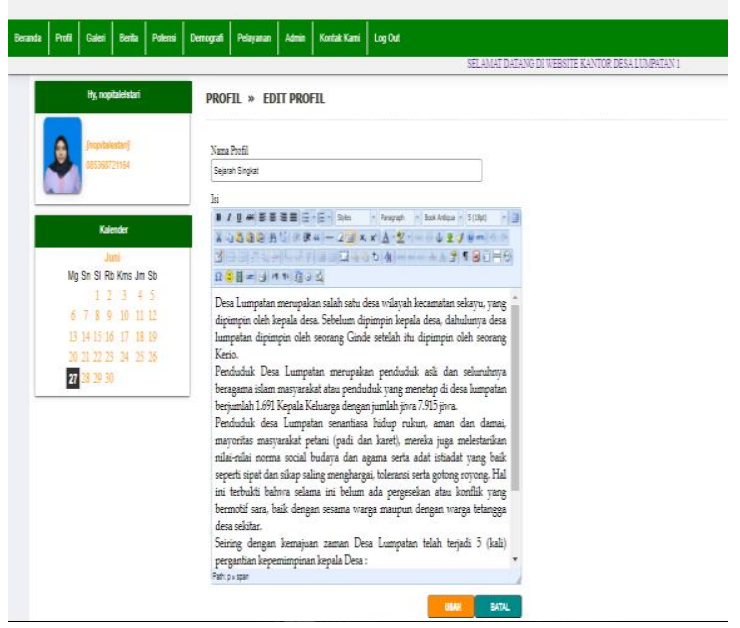

Gambar 4.5 Tampilan Edit Data Sejarah

4) Halaman Menu Profil Visi-Misi

a) Tampilan Lihat Data Visi-Misi

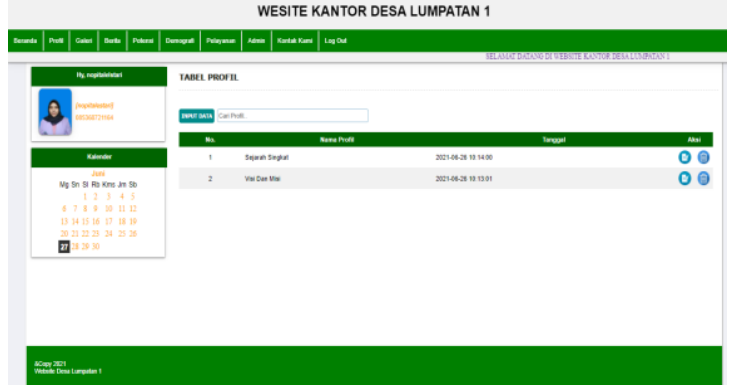

Gambar 4.6 Tampilan Lihat Data Visi-Misi

b) Tampilan Input Data Visi-Misi

Published by:

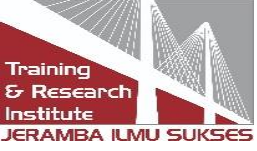




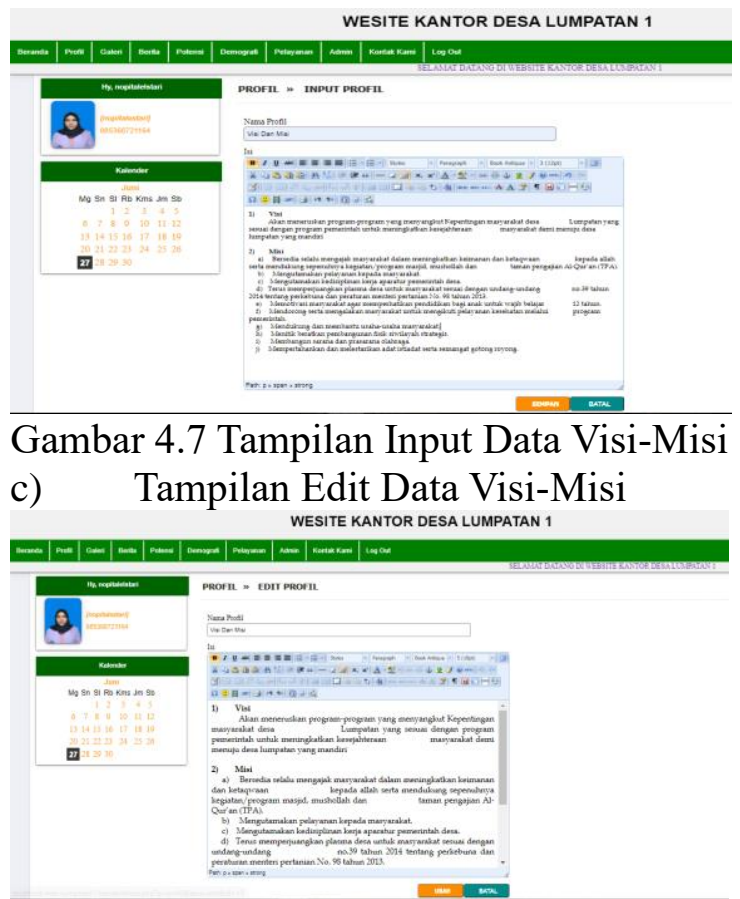

Gambar 4.8 Tampilan Edit Data Visi-Misi

5) Halaman Menu Galeri

a) Tampilan Lihat Data Galeri WESITE KANTOR DESA LUMPATAN 1

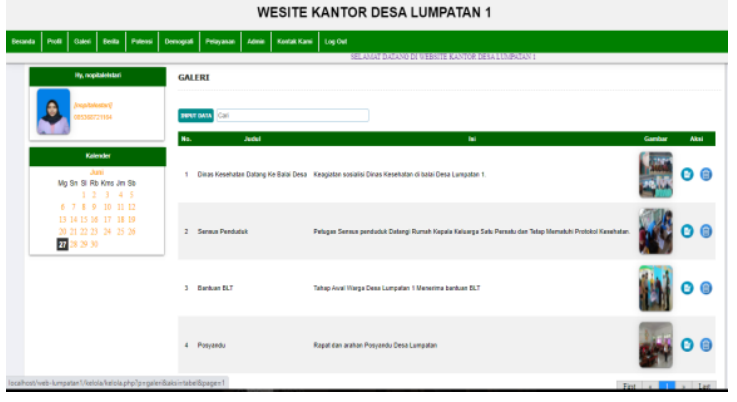

Gambar 4.9 Tampilan Lihat Data Galeri

b) Tampilan Input Data Galeri

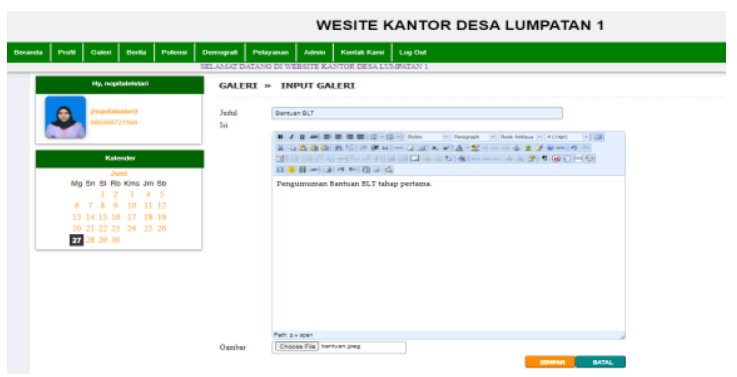

Gambar 4.10 Tampilan Input Data Galeri 
c) Tampilan Edit Data Galeri

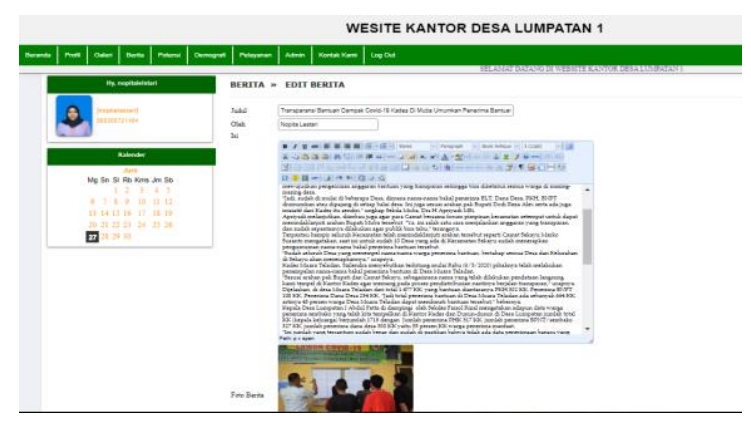

Gambar 4.11 Tampilan Edit Data Galeri

6) Halaman Menu] Berita

a) Tampilan Lihat Data Berita

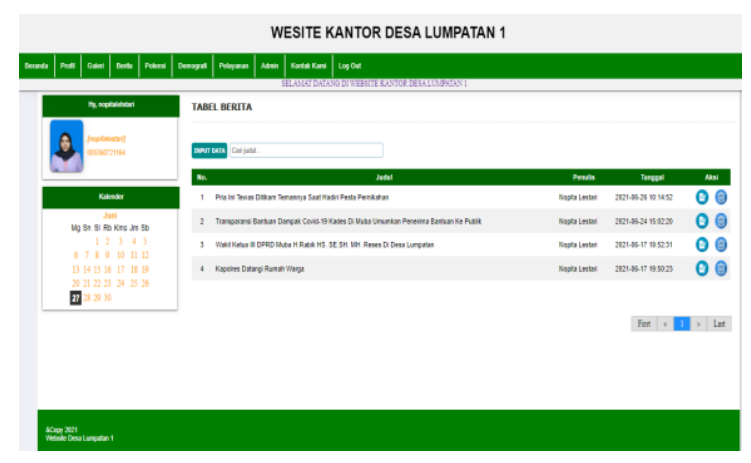

Gambar 4.12 Tampilan Lihat Data Berita

b) Tampilan Input Data Berita

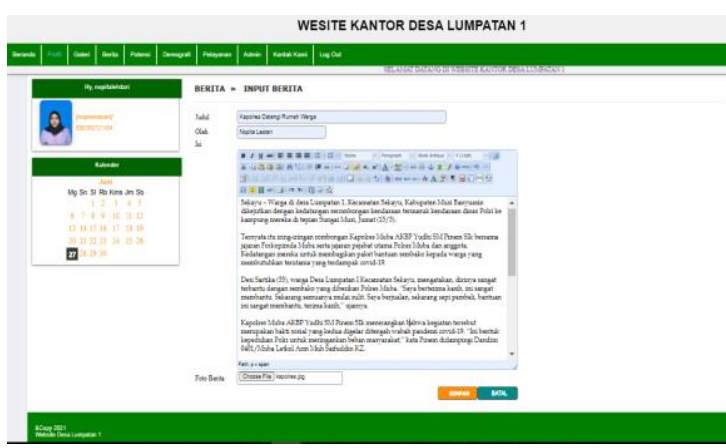

Gambar 4.13 Tampilan Input Data Berita

c) Tampilan Edit Data Berita

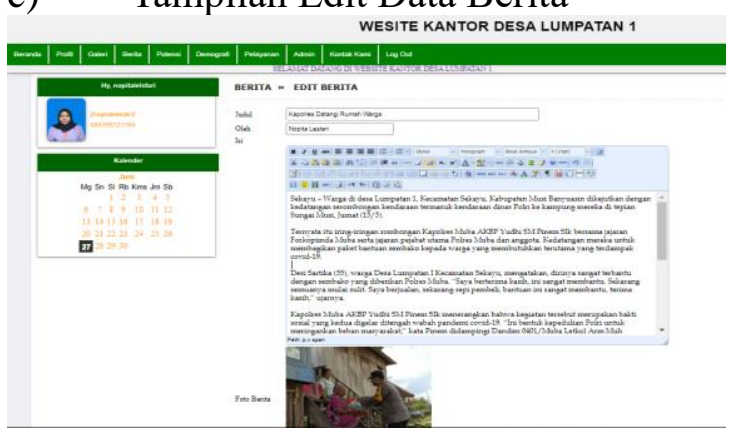

Published by: 
Gambar 4.14 Tampilan Edit Data Berita

7) Halaman Menu Potensi Desa

a) Tampilan Lihat Data Potensi Desa

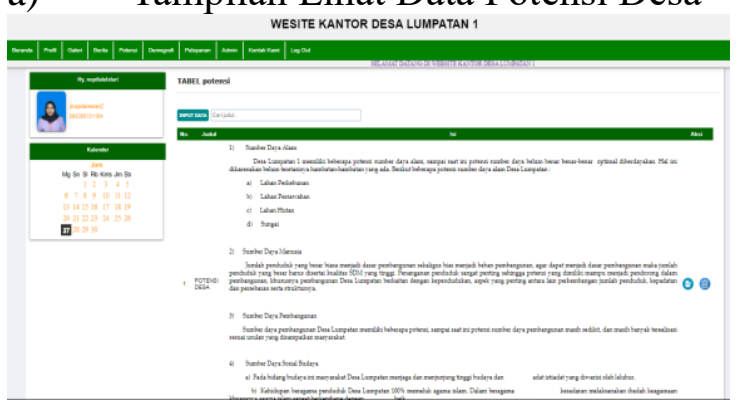

Gambar 4.15 Tampilan Lihat Data Potensi Desa

b) Tampilan Input Data Potensi Desa

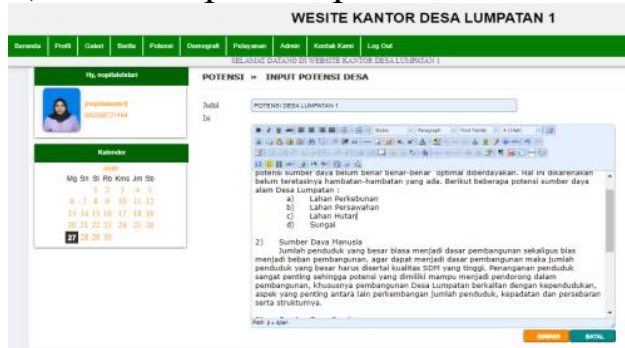

Gambar 4.16 Tampilan Input Data Potensi Desa

c) Tampilan Edit Data Potensi Desa

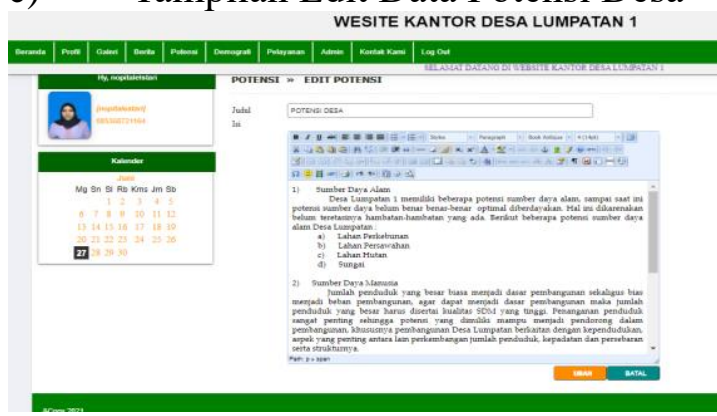

Gambar 4.17 Tampilan Edit Data Potensi Desa

8) Halaman Menu Demografi Desa

a) Tampilan Lihat Data Demografi Desa

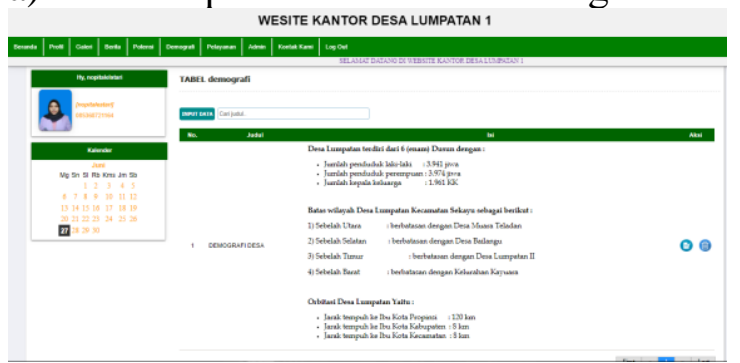

Gambar 4.18 Tampilan Lihat Data Demografi Desa 
b) Tampilan Input Data Demografi Desa

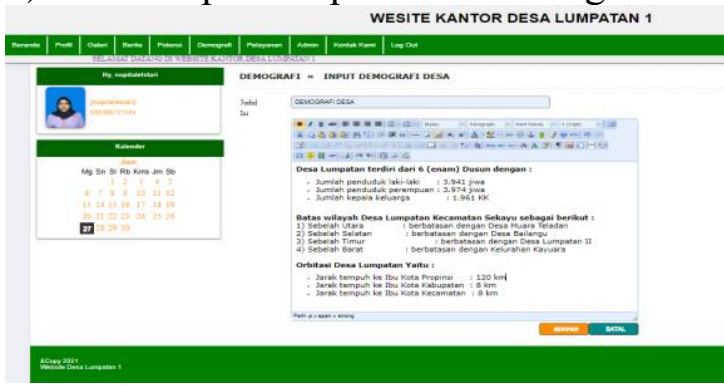

Gambar 4.19 Tampilan Input Data Demografi Desa

c) Tampilan Edit Data Demografi Desa

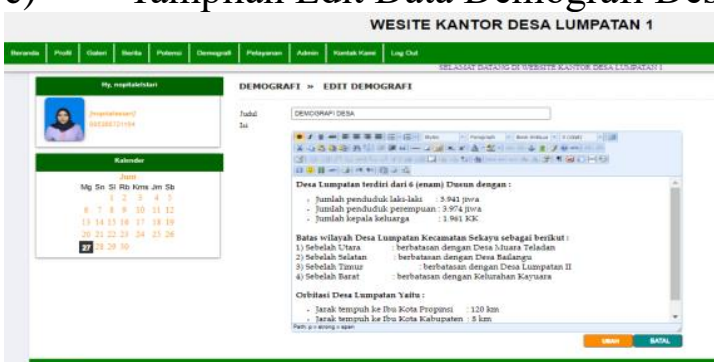

Gambar 4.20 Tampilan Edit Data Demografi Desa

9) Halaman Menu Pelayanan Surat

a) Tampilan Lihat Data Pelayanan Surat

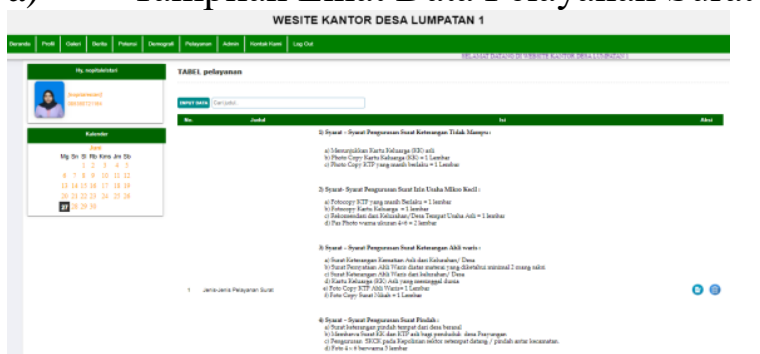

Gambar 4.21 Tampilan Lihat Data PelayananSurat

b) Tampilan Input Data Pelayanan Surat

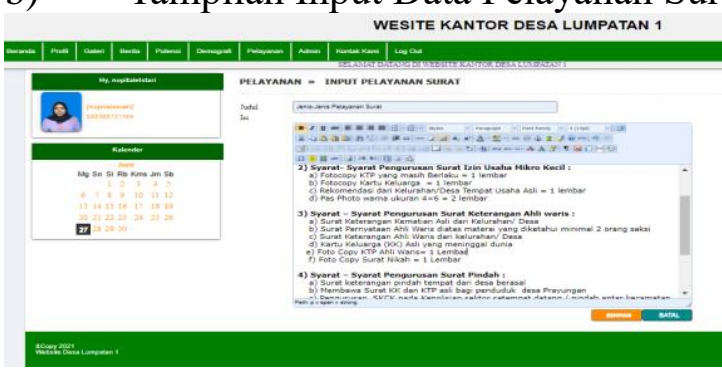

Gambar 4.22 Tampilan Input Data Pelayanan Surat 
c) Tampilan Edit Data Pelayanan Surat

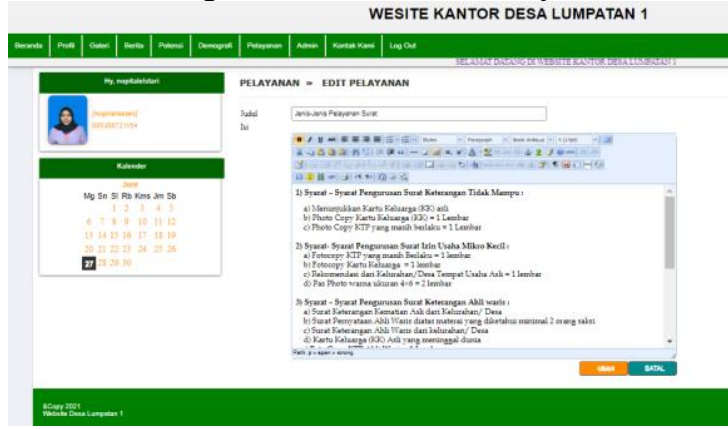

Gambar 4.23 Tampilan Edit Data Pelayanan Surat

10) Halaman Menu Kontak

a) Tampilan Lihat Data Kontak

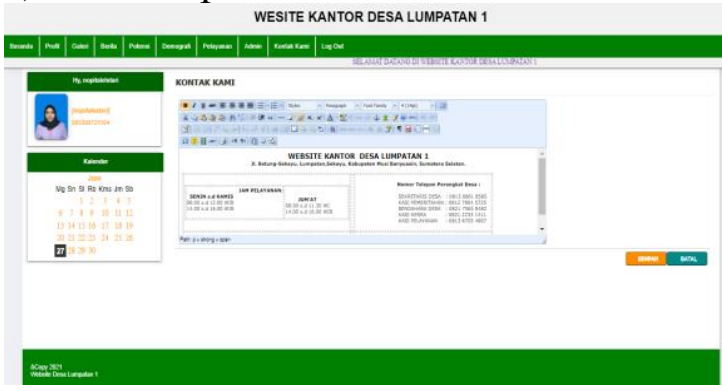

Gambar 4.24 Tampilan Lihat Data Kontak

b) Tampilan Input Data Kontak

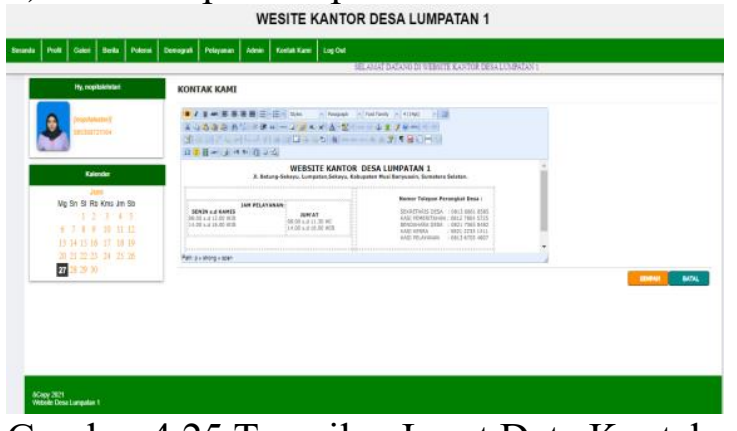

Gambar 4.25 Tampilan Input Data Kontak

c) Tampilan Edit Data Kontak

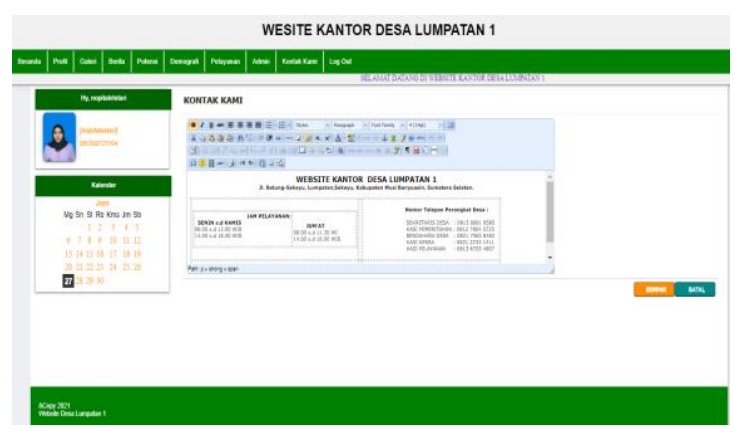

Gambar 4.26 Tampilan Edit Data Kontak

Published by: 


\subsubsection{Halaman Administrator}

1) Tampilan Halaman Beranda

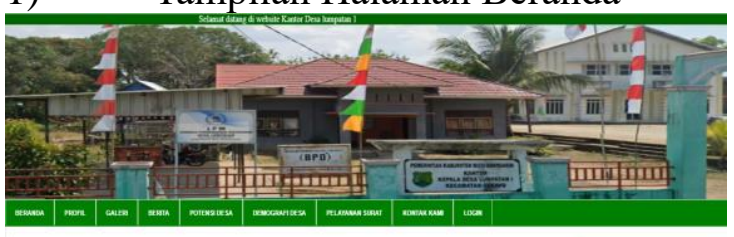

"SELAMAT DATANG DI WEBSITE RESMI DESA LUMPATAN 1"

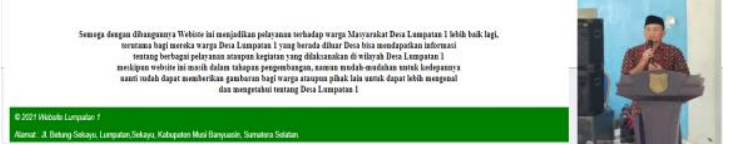

Gambar 4.27 Tampilan Halaman Beranda

2) Tampilan Halaman Menu Profil

a) Halaman Sejarah

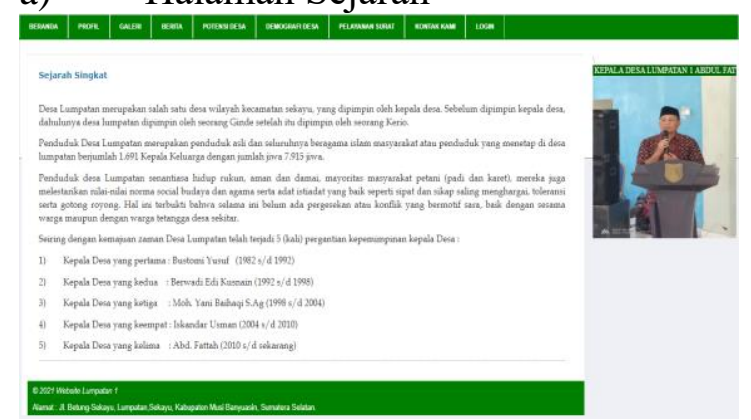

Gambar 4.28 Tampilan Halaman Sejarah

b) Halaman Visi-Misi

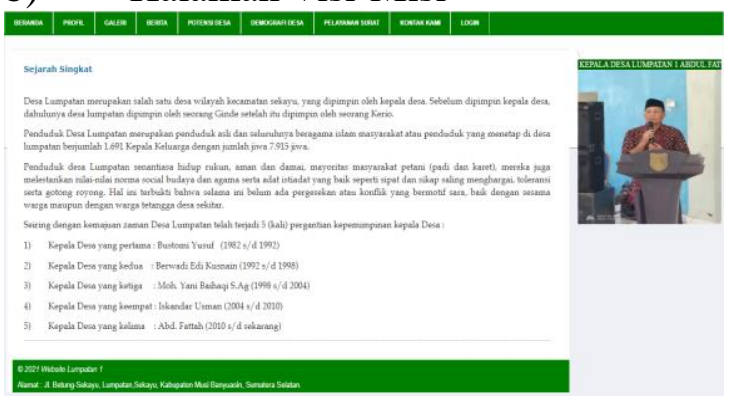

Gambar 4.29 Tampilan Halaman Visi-Misi

3) Tampilan Menu Galeri

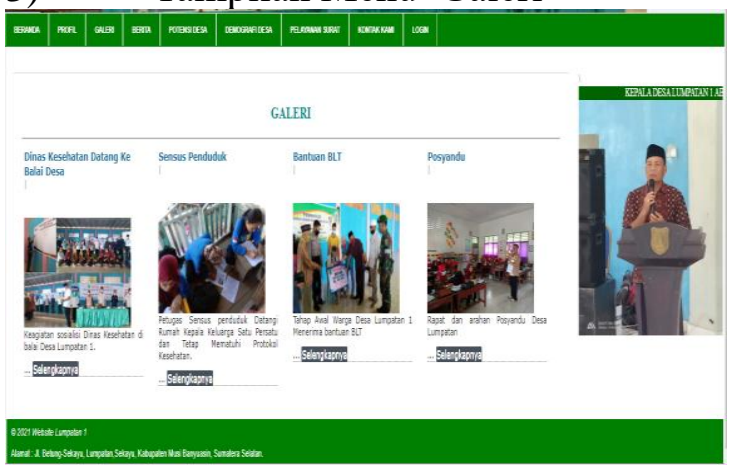

Gambar 4.30 Tampilan Halaman Galeri

Published by:

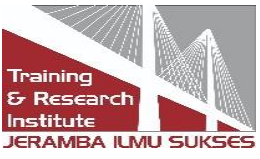




\section{4) Tampilan Menu Berita}

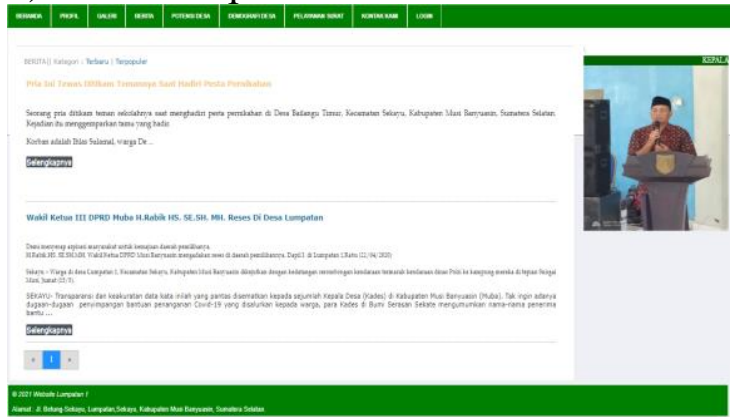

Gambar 4.31 Tampilan Halaman Berita

5) Tampilan Menu Potensi Desa

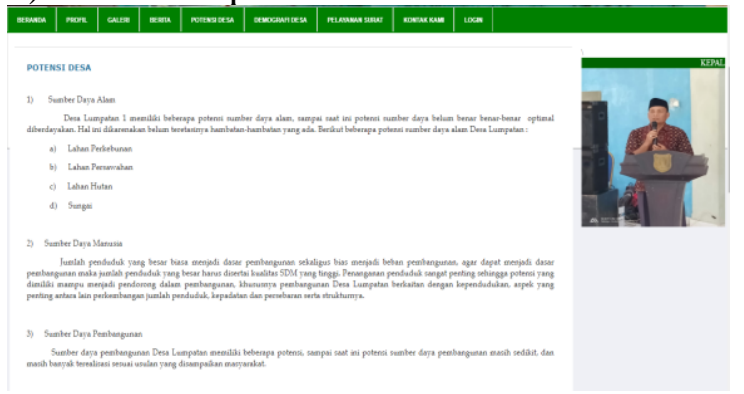

Gambar 4.32 Tampilan Halaman Potensi Desa

6) Tampilan Menu Demografi Desa

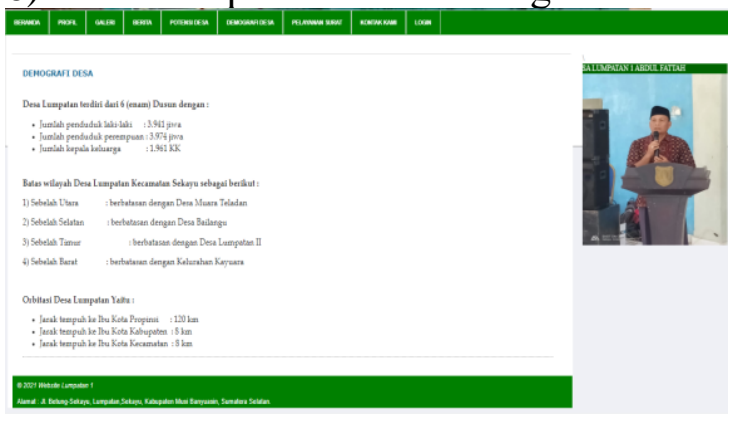

Gambar 4.33 Tampilan Halaman Demografi Desa

7) Tampilan Menu Pelayanan Surat

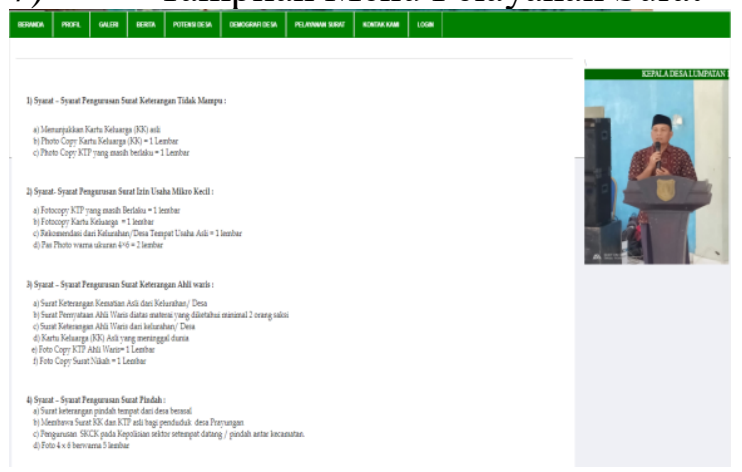

Gambar 4.34 Tampilan Halaman Pelayanan Surat

Published by: 


\begin{tabular}{r|r|lr}
$\mathrm{J}$ & $\mathrm{N}$ & $\begin{array}{l}\text { JURNAL } \\
\text { NASIONAL } \\
\text { ILMU } \\
\text { KOMPUTER }\end{array}$ & Jurnal Nasional Ilmu Komputer \\
$\mathrm{K}$ & e-ISSN: 2746-1343 \\
\hline
\end{tabular}

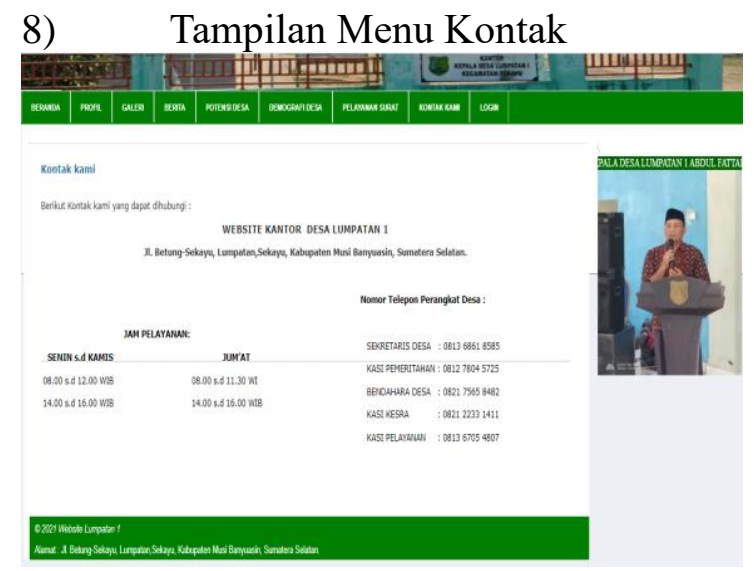

Gambar 4.35 Tampilan Halaman Kontak

\subsection{Pembahasan}

Website Company Profile Kantor Desa Lumpatan 1 ini dibuat menggunakan pemprograman $P H P$ dan database $M y S Q L$ yang digunakan untuk menyimpan data dan menginput, edit serta menghapus data pada halaman administrator. Dengan adanya website ini masyarakat umum bias melihat berbagai macam informasi terkait Kantor Desa lumpatan 1 dan mempermudah admin dalam menyebarkan informasi.

\section{Kesimpulan}

Bedasarkan tahapan yang telah dilakukan dalam perancangan Company Profile ini, maka penulis menyimpulan beberapa hal sebagai berikut:

1) Company Profile pada Kantor Desa Lumpatan 1 dibuat menggunakan bahasa pemprograman $P H P$ serta MYSQL sebagai database. Pada sistem tersebut terdapat dua halaman utama yaitu halaman admin dan halaman masyarakat.

2) Sistem ini menyediakan beberapa menu yang akan mepermudah admin dan masyarakat dalam melakukan aktivitas dan informasi yang diinginkan.

3) Company profile ini akan mempermudah Staff Kantor Desa Lumpatan 1 dalam memberikan informasi kepada masyarakat.

\section{Referensi}

Andika Mayangsari, 2017. "Perancangan Dan Pembuatan Company Profile Berbasis Website Dengan Menggunakan Wordpress Sebagai Media Promosi B2b Di Super Kitchen Mojokerto", Jurnal Aplikasi Bisnis(JAB), Politeknik Negeri Malang.

Antoni, D., \& Akbar, M. (2019). E-supply chain management value concept for the palm oil industry. Jurnal Sistem Informasi, 15(2), 15-29.

Antoni, D., Fikari, D., \& Akbar, M. (2018). The readiness of palm oil industry in enterprise resource planning. Telkomnika, 16(6), 2692-2702.

Antoni, D., Herdiansyah, M. I., Akbar, M., \& Sumitro, A. (2021). Pengembangan Infrastruktur Jaringan Untuk Meningkatkan Pelayanan Publik di Kota Palembang. JURNAL MEDIA INFORMATIKA BUDIDARMA, 5(4), 1652-1659.

Antoni, D., Jie, F., \& Abareshi, A. (2020). Critical factors in information technology 
capability for enhancing firm's environmental performance: case of Indonesian ICT sector. International Journal of Agile Systems and Management, 13(2), 159-181.

D. P., Dennis, A., \& Wixom, B. H. Tegarden, Systems Analysis and Design with UML.: John Wiley \& Sons inc, 2012.

Darmawan dan hendra, 2013, design dan pemprograman website, bandung PT.Remaja Rosdakarya.

Fauzi, F., Dencik, A. B., \& Asiati, D. I. (2019). Metodologi Penelitian untuk manajemen dan akuntansi. Jakarta: Salemba Empat.

Ginanjar Akbar, 2015. "Website Profil Sekolah Sebagai Media Informasi Dan Promosi”. Volume 4 No 1,Hal.34.

Jefri Ramadian, 2017. "Perancangan Dan Pembuatan Website Sebagai Media Promosi Company Profile Production House" Vol.13 No.1.Hal:24.

Kustiyahningsih, Yeni. 2011. Pemrograman Basis Data Berbasis WebMenggunakan PHP \& MySQL. Jakarta: Graha Ilmu.

Muhamad Jaiz. 2014. Dasar-dasar Periklanan. Cetakan Pertama. Yogyakarta: Graha Ilmu.

Mustaqbal, M., Sidi. 2015. "Pengujian Aplikasi Menggunakan Black Box Testing Boundary Value Analisys" (Studi Kasus: Aplikasi Prediksi Kelulusan SNMPTN), Jurnal Ilmiah Teknologi Informasi Terapan, Vo.1, No.3, Hal.3 Hal 32-33.

Prayoga Pribadi, 2011. "Rancangan Bangun Website Sebagai Sarana Promosi Peroperti" Volume 4 No 2,Hal.47..

Priyanto, Jauhari. 2015. Pemprograman Web. Cetakan Kedua. Bandung : INFORMATIKA

Puryanto, 2013. "Pembangun Website Pada Desa Nangsri”. Vol.02, No.01, Hal.64.

Riyadi, dkk. 2016. Analisis dan Desain Sistem Informasi Pemasaran. 38, (2), hal 5.

Slamet Riyanto, 2018. "Rancang Bangun Website Desa Kresek-Madiun Untuk Media Informasi Potensi Wisata Alam Dan Kulinier" Vol. 1 No. 2, Hal.43.

Soegijanto \& Lestari, hutami ageng 2016, Aplikasi Company Profile Digital PT.Minnara Sejahtera Raya Jakarta, Jurnal ilmiah KOMPUTASI Volume 15 Nomor :2,18.

Trivena \& Agus, 2016, Evaluasi Strategi Promosi dan penjualan Terhadap Keunggulan Bersaing Pada PT. Astragraphia,TBK Cabang Manado. Jurnal EMBA. 4(2), 134.

Wardana. 2010. Menjadi Master PHP Dengan Framework Codeigniter. Jakarta: Elex Media Komputindo.

Wiswakarma, Komang.2010. Panduan Lengkap Menguasai Pemrograman CSS. Yogyakarta: Lokomedia.

\section{Copyrights}

Copyright for this article is retained by the author(s), with first publication rights granted to the journal.

This is an open-access article distributed under the terms and conditions of the Creative Commons Attribution license (http://creativecommons.org/licenses/by/4.0/) 
